\title{
Modelagem e retroanálise do comportamento térmico do concreto em protótipo $\epsilon$ fundação in loco
}

\author{
PATRÍCIA GUEDES GAMBALE - MEstre \\ Concrecon Concreto e Construções Ltda.
}

\author{
EDUARDO DE AQUINO GAMBALE - ESPECIALISTA \\ NICOLE PAGAN HASPARYK - DOUTORA \\ Eletrobras Furnas
}

\author{
JEFERSON LUIZ BRONHOLO - MESTRE
}

\section{RESUMO}

O MONITORAMENTO DO COMPORTAMENTO TÉRMICO DO CONCRETO NAS PRIMEIRAS IDADES É MUITO IMPORTANTE PELO FATO DE QUE SE PODEM DEFINIR PRECOCEMENTE RISCOS FUTUROS DE FISSURAÇÕES DEVIDO À GERAÇÃO DE CALOR INTERNO EM DECORRÊNCIA DA HIDRATAÇÃO DO CIMENTO. ESTE TRABALHO TEM POR OBJETIVO MODELAR O COMPORTAMENTO DAS TEMPERATURAS GERADAS NO INTERIOR DA MASSA DE CONCRETO E REALIZAR RETROANÁLISE. PARA TANTO, FOI CONFECCIONADO UM PROTÓTIPO DE CONCRETO CONTENDO CIMENTO DO TIPO CP V E UM BLOCO DE FUNDAÇÃO EM CAMPO UTILIZANDO CIMENTO DO TIPO CP II-F. AS TEMPERATURAS FORAM AVALIADAS POR MEIO
DE TERMOPARES INSTALADOS INTERNAMENTE. AS MODELAGENS FORAM REALIZADAS TANTO PARA O PROTÓTIPO COMO PARA UM CASO REAL DE FUNDAÇÃO DE FORMA A CONFRONTAR OS DADOS OBTIDOS, ALÉM DE TER SIDO ANALISADA A PROBABILIDADE DE INCIDÊNCIA DE FISSURAS DE ORIGEM TÉRMICA. OS RESULTADOS REFORÇAM A IMPORTÂNCIA DE UM ESTUDO PRELIMINAR DO COMPORTAMENTO TÉRMICO DO CONCRETO POR MEIO DE MODELAGENS E ENSAIOS DE FORMA A ATUAR PREVENTIVAMENTE, MITIGANDO A FISSURAÇÃO DE ORIGEM TÉRMICA, BEM COMO OUTRAS MANIFESTAÇÕES PATOLÓGICAS ENVOLVENDO REAÇÕES QUIIMICAS EXPANSIVAS.

Palavras-chave: concreto, comportamento térmico, calor de hidratação, modelagem, fundação.

\section{INTRODUÇÃOO}

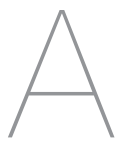

s reações químicas decorrentes da hidratação do cimento possuem natureza exotérmica e o calor gerado vai variar em função do tipo de composto da composição química do cimento envolvido (MEHTA; MONTEIRO, 2014). Os picos de temperatura que um concreto pode alcançar em decorrência dessas reações exotérmicas também podem variam em função de vários fatores e, em especial, da composição química e do tipo de cimento empregado, finura e consumo do aglomerante (GAMBALE 2015; GAMBALE et al., 2019). Qualquer concreto pode atingir elevadas temperaturas sem, necessariamente, ser curado termicamente. Concretos massa, bem como aqueles contendo elevados consumos de cimento, e os confeccionados com cimentos de alta resistência inicial, são mais susceptíveis ao atingimento de elevadas temperaturas.

Taxas de aquecimento e resfriamento mais altas podem trazer riscos de fissuração ao concreto. A partir do momento em que a temperatura máxima atingida tender ao equilíbrio térmico com o ambiente, surgirão as tensões de tração, trazendo riscos de fissuração, caso seus valores superem a sua capacidade resistente.
As fissuras geradas nessa etapa podem trazer para o elemento estrutural reflexos negativos no seu desempenho e durabilidade. Isso porque, com a formação de caminhos preferenciais para a água e outros agentes externos, por meio da percolação através das fissuras, pode-se comprometer mais ainda a qualidade do concreto. Desta forma, além da fissuração inicial pelo comportamento térmico inadequado atingido pelo concreto e redução da sua capacidade resistente, outras manifestações patológicas poderão se instalar na estrutura, agregando mais danos estruturais e afetando, por conseguinte, a vida útil. (SCHOVANZ et al., 2021). 
Considerando, por exemplo, blocos de transição e fundação, elementos esses estruturais que suportam uma edificação, torna-se imprescindível a avaliação prévia do potencial comportamento térmico do concreto a ser empregado de forma a evitar possíveis, danos bem como riscos de colapsos (GAMBALE et al., 2019).

Diante do exposto, este trabalho apresenta resultados de calibração de modelo para predizer o nível de temperatura que pode ser atingido no interior do concreto em diferentes condições, bem como resultados reais de estruturas que sofreram elevadas temperaturas e riscos de redução de vida útil.

\section{PROGRAMA EXPERIMENTAL}

\section{I Variáveis estudadas}

As variáveis estudadas neste programa experimental, visando atingir os objetivos do trabalho, são o tipo e o consumo do cimento empregado no concreto.

\section{I.I TIPO DE CIMENTO}

Para a realização desse trabalho, foram utilizados os cimentos Portland $\mathrm{CP}$ V-ARI e o cimento Portland CP II F-40. No protótipo do bloco, foi utilizado o cimento CP V-ARI, por apresentar um comportamento mais agressivo no que diz respeito às temperaturas geradas pelo calor de hidratação, e a escolha pelo cimento Portland CP || F-40 para aplicação em campo, justifica-se pelo fato de ser o cimento mais comumente empregado no estado de Goiás, região do estudo.

\section{I.2 CoNSUMO DE CIMENTO}

No protótipo do bloco, foi utiliza-
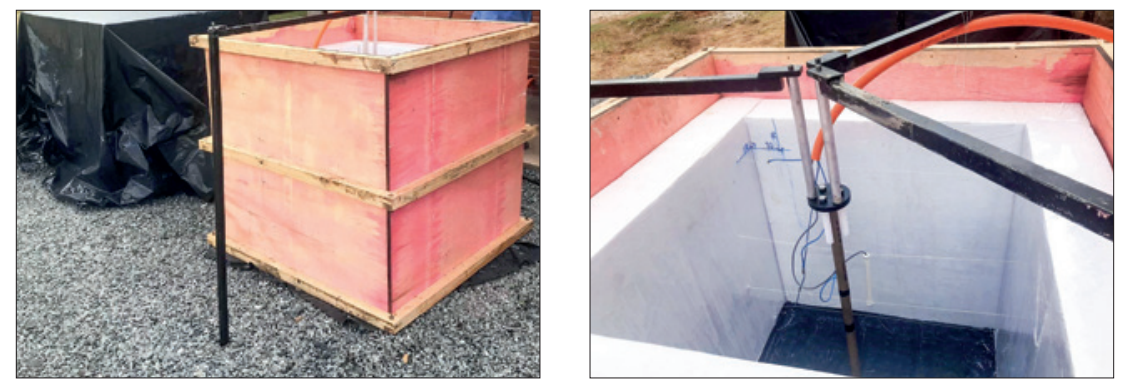

Figura 1

Protótipo do bloco a ser concretado e termopares instalados em seu interior, para o monitoramento da temperatura, além dos extensômetros - área de envelhecimento de Furnas - GO

Fonte: FURNAS

do um consumo de cimento Portland CP V-ARI igual a $471 \mathrm{~kg} / \mathrm{m}^{3}$; já na análise de campo, utilizou-se um consumo de $315 \mathrm{~kg} / \mathrm{m}^{3}$ de aglomerante, sendo o cimento Portland, do tipo CP II F-40, e ainda a adição de 10\% de sílica ativa em substituição à massa de cimento, com o intuito de atender a resistência solicitada em projeto, e visando a um menor consumo do aglomerante hidráulico.

\subsection{Materiais empregados}

Para confeccionar os concretos utilizados neste trabalho, foram empregados os dois tipos de cimento Portland citados anteriormente, além de agregados graúdos graníticos e miúdos, disponíveis no estado de Goiás. A caracterização dos materiais foi baseada na referência Equipe de FURNAS - Editor Walton Pacelli de Andrade (1997).

\subsection{Método}

\subsection{PROTÓTIPO}

Após a realização de todas as caracterizações dos materiais com- ponentes dos concretos estudados e desenvolvidos os traços de concreto, foram concretados alguns protótipos de bloco de fundação em duas áreas de envelhecimento natural por meio de um projeto de P\&D Furnas Aneel intitulado "Metodologias e infraestrutura tecnológica para aperfeiçoamento das avaliações de confiabilidade e otimização de empreendimentos de energia" (Hasparyk et al., 2021). Uma área está localizada no estado de Goiás (nas dependências de Furnas), e a outra no estado do Paraná (dentro das instalações do Lactec). Os blocos eram cúbicos e continham as dimensões de 0,80 × 0,80 × 0,80 metros, conforme apresentado na Figura 1.

Com o intuito de diminuir a dispersão da temperatura interna do bloco, gerada pelo efeito exotérmico decorrente do processo de hidratação do cimento, foram utilizadas placas de isopor revestindo as laterais internas da fôrma (Projeto de P\&D FURNAS ANEEL).

De forma a monitorar a curva exotérmica, foram instalados do interior do bloco quatro termopares, em locais variados, incluindo um no centro do bloco. 

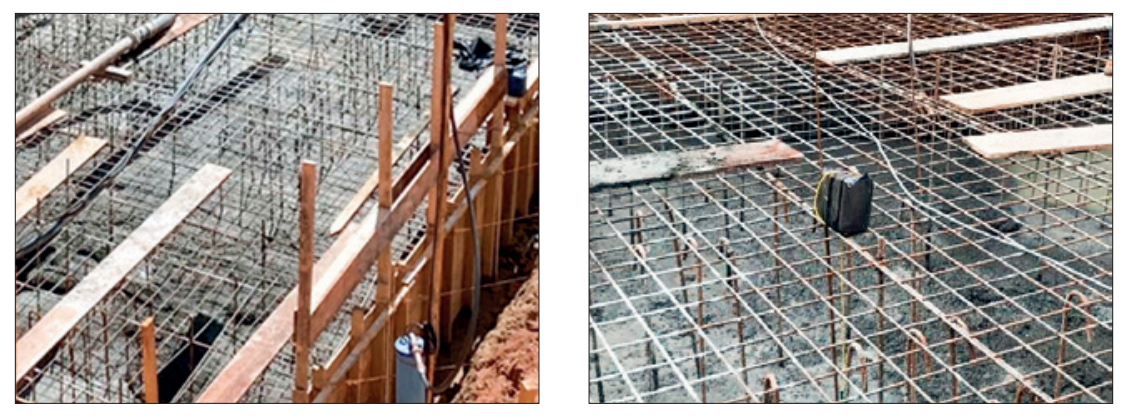

\section{Figura 2}

Foto de parte do bloco concretado (à esquerda) e termopar instalado no centro (à direita) para o monitoramento interno de temperatura

Para o monitoramento ao longo do tempo em relação às possíveis expansões geradas por tensões internas, foram instalados um extensômetro de haste (específico e desenvolvido pelo projeto de P\&D Furnas) e um extensômetro elétrico tipo Carlson (M-8).

\subsubsection{BLOCO DE FUNDAÇÃO DE OBRA} no Estado de Golás

Foi também monitorado em campo um bloco de fundação localizado em obra de edificação (Estado de Goiás) para posterior retroanálise térmica. $\mathrm{Na}$ Figura 2, observa-se foto do bloco concretado e detalhe do termopar instalado para o monitoramento das temperaturas no centro do bloco.

O bloco de fundação em análise foi concretado em camadas, com volume de aproximadamente $100 \mathrm{~m}^{3}$ nas duas primeiras camadas e altura aproximada de $80 \mathrm{~cm}$, e de $140 \mathrm{~m}^{3}$ na última camada, com altura aproximada de 1 metro.

O traço do concreto utilizado no bloco $(1: 2,7: 3,7)$ contemplou um consumo de cimento de $315 \mathrm{~kg} / \mathrm{m}^{3}$ (tipo CP II F-40), 10\% de sílica ativa em substituição ao cimento (em massa), além de aditivos do tipo superplastificante e polifuncional. A relação água cimento manteve-se em 0,52.

Algumas metodologias de estudo de dosagem, como a utilizada no Laboratório de Concreto de Furnas Centrais Elétricas S.A (GST.E Aparecida de Goiânia/GO) trabalham com a proporção de aglomerante no concreto (cimento com adição) por meio da definição de cimento equivalente. Para se calcular o consumo de cimento equivalente no traço, de modo a poder utilizar esse dado no modelo de previsão, a Equação 1 foi adotada (EQUIPE DE FURNAS, 1997). $C_{e q}=M_{c i m}+\frac{\left(\gamma_{c} \cdot M_{a d}\right)}{\gamma_{a d}}$

\section{Onde}

$\mathrm{C}_{\text {eq }}=$ cimento equivalente $\left(\mathrm{kg} / \mathrm{m}^{3}\right)$;

$M_{\text {cim }}=$ massa de cimento (kg);

$\mathrm{M}_{\mathrm{ad}}=$ massa de adição (kg);

$\gamma_{c}=$ massa específica do cimento $\left(\mathrm{kg} / \mathrm{m}^{3}\right)$; $M_{a d}=$ massa específica da adição $\left(\mathrm{kg} / \mathrm{m}^{3}\right)$.

\section{MODELAGEM}

O modelo de previsão proposto pela pesquisa foi desenvolvido com base em modelo apresentado e utilizado por Gambale (2015) para a avaliação de temperatura máxima e da tensão em concretos de características massivas. São colocados todos os dados de entradas necessários para a análise, sendo de grande importância

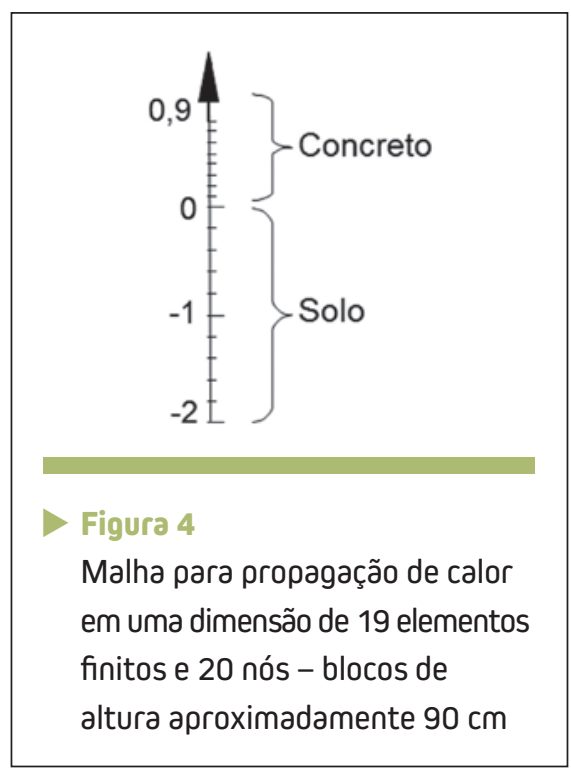

Figura 3

Malha para propagação de calor em duas dimensões de 64 elementos finitos e 81 nós - blocos de 80 × $80 \mathrm{~cm}$ 


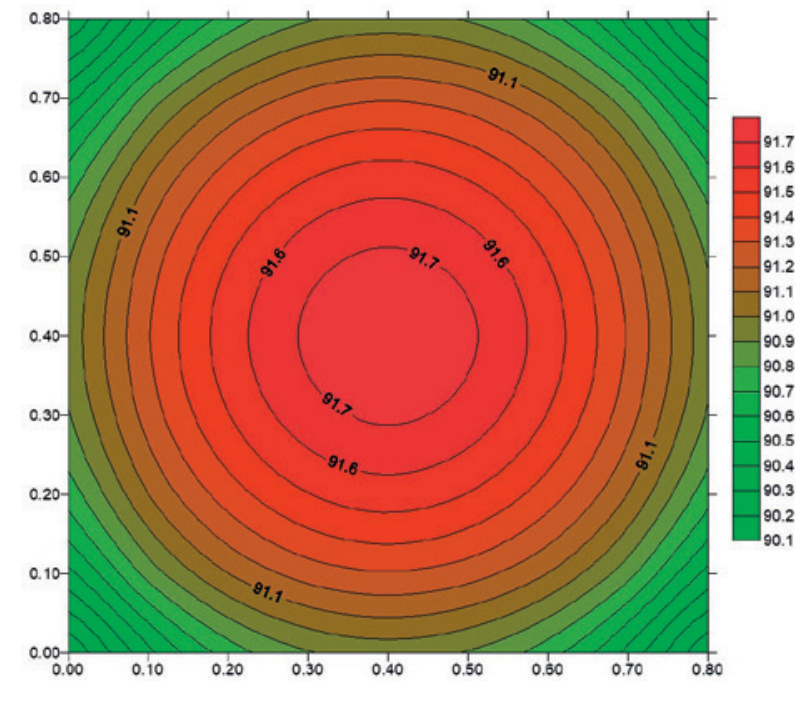

Figura 5

Isoterma do bloco de 80 × 80 × $80 \mathrm{~cm}$ na idade em que ocorreu a temperatura máxima
As malhas de elementos finitos utilizadas nas simulações estão mostradas nas Figuras 3 e 4.

○ problema da condução térmica utilizado na modelagem do calor é baseado na resolução numérica da equação de propagação de calor em o conhecimento das propriedades físicas, mecânicas e térmicas do concreto. Como resultado final, se tem a temperatura máxima e a probabilidade de fissuração. Na Figuras 5 e 6, é possível verificar a isoterma do protótipo na idade em que ocorreu essa máxima temperatura e a evolução da temperatura no bloco em campo, respectivamente. Para a comparação do modelo proposto pela pesquisa, avaliou-se a propagação de calor em uma dimensão para o estudo em campo, e duas dimensões para o estudo em protótipos. um meio sólido (Equação 2), deduzida da Lei de Fourier para propagação de calor, e o princípio de conservação de energia. A equação constitutiva do fenômeno é mostrada a seguir:

[2]

$$
\frac{\delta \theta}{\delta \mathrm{t}}=h^{2} \cdot \frac{\delta^{2} \theta}{\delta \mathrm{z}^{2}}+\frac{\delta \mathrm{T}}{\delta}
$$

Onde:

$\delta_{\theta}=$ temperatura do elemento de volume considerado;

$\delta_{\mathrm{t}}=$ variável tempo; $\mathrm{z}=$ coordenada na direção do fluxo;

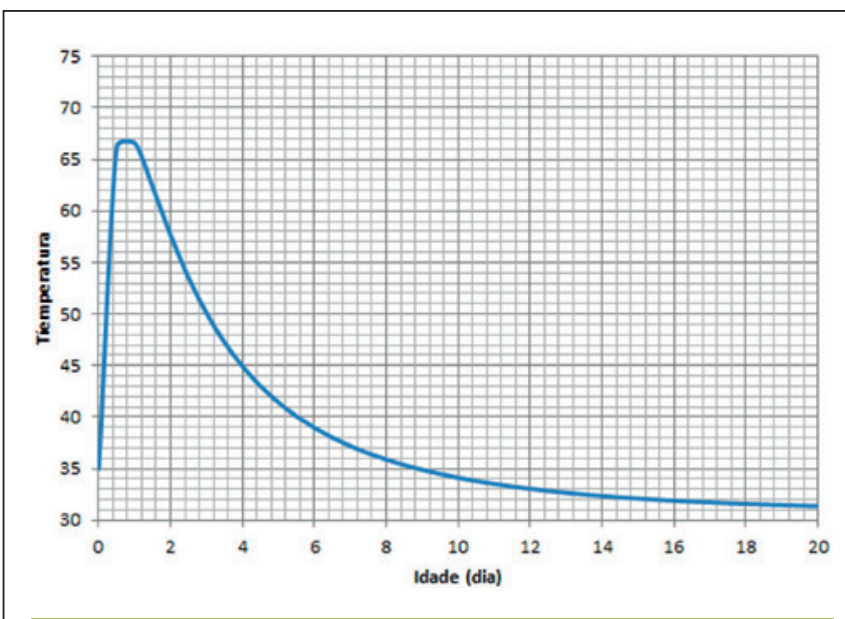

Figura 6

Evolução da temperatura no bloco monitorado em campo
T = subida adiabática da temperatura no elemento de volume do concreto em questão;

$\mathrm{h}^{2}=$ difusividade térmica.

O resultado do modelo matemático que rege o comportamento do concreto foi ajustado com base no trabalho de WU et al. (2011), no que se refere a determinação do tempo equivalente.

\section{MONITORAMENTO E RETROANÁLISE}

As Figuras 7 e 8 mostram a boa aderência entre os resultados do monitoramento e a modelagem executada (TR - Temperatura real, em vários pontos).

\section{CONSIDERAÇÕES}

Os modelos empregados se aderiram bem aos dados reais, que foram obtidos a partir das leituras de campo e nos protótipos, por meio de termopares.

No campo foi observada fissura, conforme mostram as Figuras 9 e 10. Para uma análise mais detalhada internamente, foi extraído um testemunho

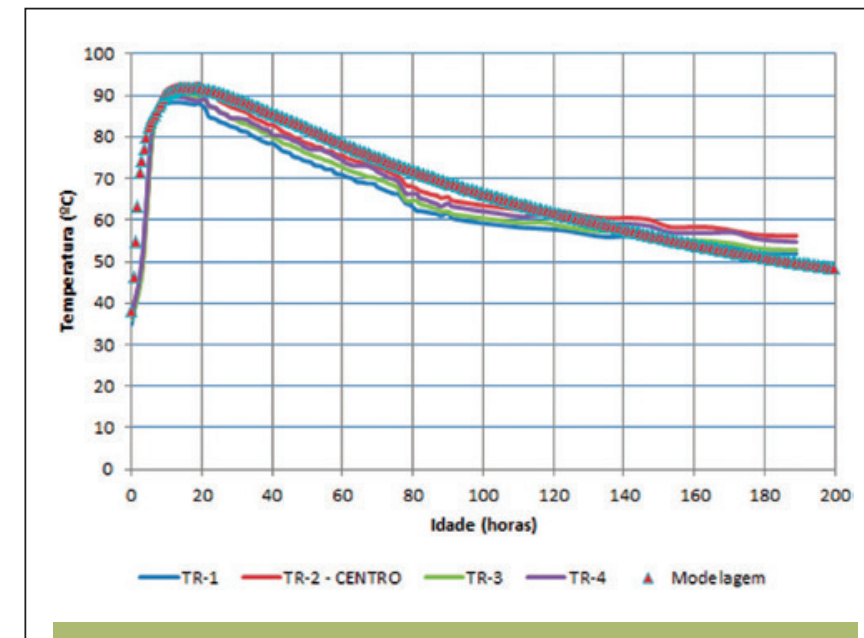

\section{Figura 7}

Evolução da temperatura medida em quatro pontos no interior de um bloco - Protótipo (bloco de 80 × 80 × $80 \mathrm{~cm}$ ) localizado no estado do Paraná, comparado com a curva obtida a partir da modelagem

Fonte: Projeto de P\&D Furnas/Aneel 


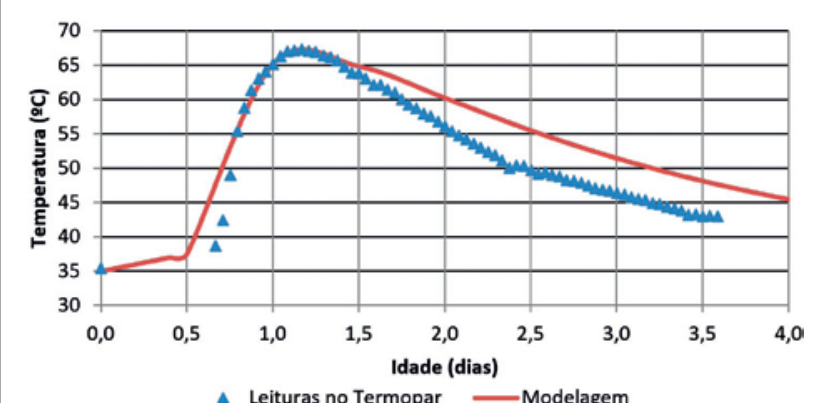

4 Leituras no Termopar $\longrightarrow$ Modelagem

\section{Figura 8}

Evolução da temperatura do bloco concretado em campo com o termopar instalado no centro para o monitoramento de temperatura e do modelo ultrapassar a capacidade de deformação máxima do concreto, fissuras podem ser induzidas antes mesmo da estrutura atingir a sua máxima de temperatura, ou seja, antes que a temperatura do bloco esteja em processo de de concreto sobre a fissura visando verificar a profundidade da mesma e a sua característica. Percebeu-se que a fissura estava presente ao longo de toda a profundidade, na camada recém-concretada e, internamente, apresentava-se com uma abertura maior que externamente. A fissura surgiu no dia seguinte à concretagem e existem algumas causas possíveis e ainda a serem melhor exploradas e investigadas. Uma hipótese está relacionada à alta temperatura atingida pelo concreto, na região central, trazendo um diferencial importante em relação à superfície, e outra, de movimentação das formas e/ou armaduras durante a concretagem, ou mesmo a combinação desses fatores. Ainda, de acordo com ACl 207 (2007), quando o gradiente de temperatura entre centro de gravidade da estrutura e a superfície for suficiente para

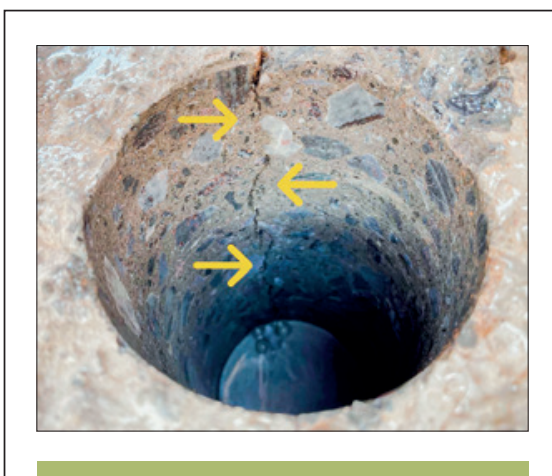

Figura 10

Detalhe interno do furo de extração e da fissura na superfície do bloco, observada em campo estabilização com aquela do ambiente, após resfriamento.

As temperaturas atingidas nos dois blocos foram elevadas e ficaram acima de $65^{\circ} \mathrm{C}$. Além das tensões elevadas de origem térmica, com consequente fissuração potencial do concreto, riscos de formação da etringita tardia (DEF) ao longo do tempo são elevadíssimos. Quanto ao bloco protótipo, ainda não foram observadas fissuras visualmente, no entanto, existe risco futuro de DEF e danos ao bloco, com reflexos no comportamento mecânico e incidência de deformação do concreto ao longo do tempo, por meio de um ataque interno por sulfatos em decorrência de alto calor interno atingido.

Comparando os consumos de cimento de $471 \mathrm{~kg} / \mathrm{m}^{3}$ com o cimento do tipo CP V-ARI e o de $315 \mathrm{~kg} / \mathrm{m}^{3}$ para o CP I| F-40 com 10\% de sílica ativa, como esperado, o concreto com maior consumo (protótipo) apresentou valores mais expressivos e maiores de temperatura máxima, chegando a $96^{\circ} \mathrm{C}$ no centro do bloco. Porém, o concreto contendo um consumo menor também atingiu temperaturas elevadas, chegando a $67,3^{\circ} \mathrm{C}$, apesar de ter sido usado um cimento do tipo CP II-F em combinação com pozolana. Assim, cuidados devem ser tomados quanto às elevações de temperatura e aos riscos de fissuração de origem térmica no concreto, bem como o desenvolvimento da DEF no tempo. O fato de o protótipo não
Figura 9

Fissura ao longo de toda a extensão do testemunho de concreto, observada em campo

ter apresentado fissuração de origem térmica está relacionado ao cuidado no resfriamento lento ocorrido (houve a manutenção do isopor entre concreto e forma, sendo assim as taxas de resfriamento foram controladas e se mantiveram bem mais baixas), atingindo, portanto, menores gradientes de temperatura e uma dissipação mais lenta e gradual do calor interno, aliviando assim as tensões de origem térmica. Ainda, o protótipo foi desenvolvido em pesquisa com o intuito justamente de propiciar apenas a DEF (Hasparyk et al. , 2021), a partir de elevada temperatura de pico, porém, isolando as tensões de origem térmica e fissurações em decorrência dessas. Nesse caso, foi feito uso de um cimento com comportamento mais agressivo para o fenômeno da DEF (pelo tipo empregado, bem como as suas características físico-químicas), ocasionado pelas elevadas temperaturas

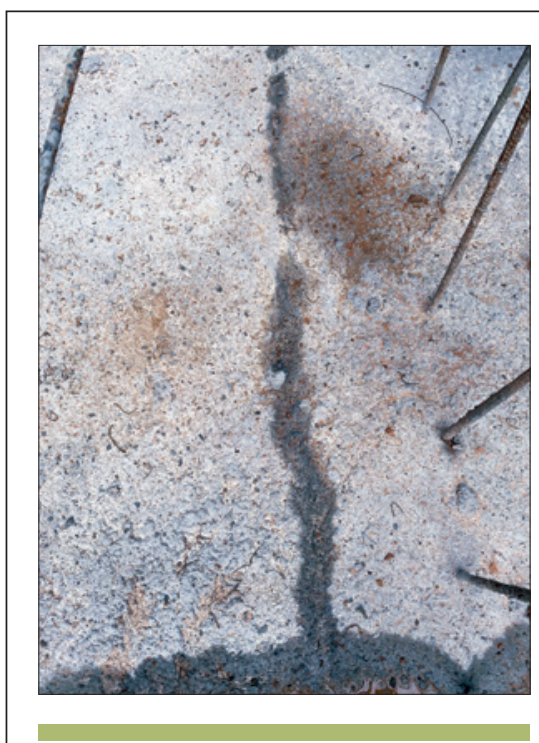

Figura 11

Detalhe da fissura no bloco, observada em campo 
geradas em decorrência do seu calor de hidratação. Por outro lado, para o bloco concretado em campo, as definições do construtor não contemplaram a adoção de sistemas de refrigeração haja vista o emprego de um cimento do tipo CP II-F-40 e a incorporação de
10\% de sílica ativa, o que não foi suficiente para manutenção de valores de temperatura abaixo de $65^{\circ} \mathrm{C}$, trazendo além de potencial para a DEF, fissurações de origem térmica. Para ambas as situações, a prática recomendada seria a adoção de sistemas de refrige- ração para garantir a temperatura de pico abaixo de $60-65^{\circ} \mathrm{C}$.

\section{AGRADECIMENTOS}

Agradecimentos especiais à FURNAS e ao LACTEC, e ao projeto de P\&D FURNAS ANEEL.

\section{PRFERÊNCIAS BIBLIOGRÁFICAS}

[1] ACl: AMERICAN CONCRETE INSTITUTE (2007). Report on thermal and volume change effects on cracking of mass concrete. ACI, Farmington Hills.

[2] Equipe de FURNAS - Editor Walton Pacelli de Andrade (1997).Concretos: Massa, Estrutural, Projetado e Compactado com Rolo - Ensaios e Propriedades. Ed. Pini, São Paulo-SP.

[3] GAMBALE,P.G. (2017). Estudo do calor de hidratação do massa e contribuição ao cálculo térmico e à previsão de fissuras de retração. Tese Mestre em Geotecnia, Estruturas e Construção Civil pela UFG, Goiânia.

[4] HASPARYK, N.P.; KUPERMAN, S.C.; BRONHOLO, J.L. et al. (2021). Concrete block sites in Brazil for assessing ASR, ISA and coupled attack over time. In: 16th International Conference on Alkali-Aggregate Reaction in Concrete (16 ICAAR. 2020-2022), Ed. Batista, A.L.; Silva, A.S.; Fernandes, I.; Santos, L.O.; Custódio, J.C.; Serra, C. LNEC, Proceedings, v. 1, LNEC, Lisboa, Portugal.

[5] MEHTA, P. K.; MONTEIRO, P. J. M. Concreto: estrutura, propriedades e materiais. 2ª ed. HASPARYK, N. P. (Ed.). São Paulo: IBRACON, 2014.

[6] GAMBALE, E. A. Avaliação da temperatura máxima em estruturas executadas com concreto massa. In: $57^{\circ}$ CONGRESSO BRASILEIRO DO CONCRETO, 2015, Bonito-MS.

7] GAMBALE, P. G.; GAMBALE, E. A.; HASPARYK, N. P.; KUPERMAN, S. C.; Análises térmicas em blocos de concretos e avaliação da presença de DEF. In: $61^{\circ}$ CONGRESSO BRASILEIRO DO CONCRETO, 2019, Fortaleza-CE.

[8] WU, S. HUANG, D. LIN, F.B. (2011). Estimation of cracking risk of concrete at early age based on thermal stress analysis. J Therm Anal Calorim. Hungria. p. 171-186.

[9] SCHOVANZ, F. D., TIECHER,F., HASPARYK, N. P., KUPERMAN,S., LERMEN, R. T. (2021). Evaluation of delayed ettringite formation through physical, mechanical, and microstructural assays. ACI Materials Journal/January 2021.

\section{Sistemas de Fôrmas para Edifícios}

Recomendações para a melhoria da qualidade e da produtividade com redução de custos

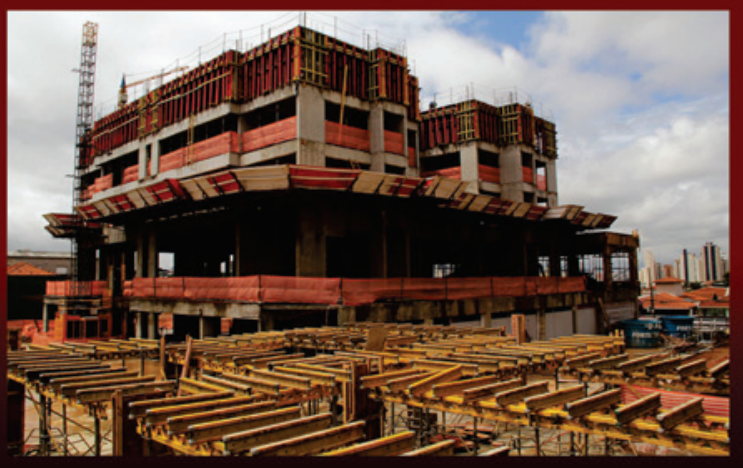

ANTONIO CARLOS ZORZI

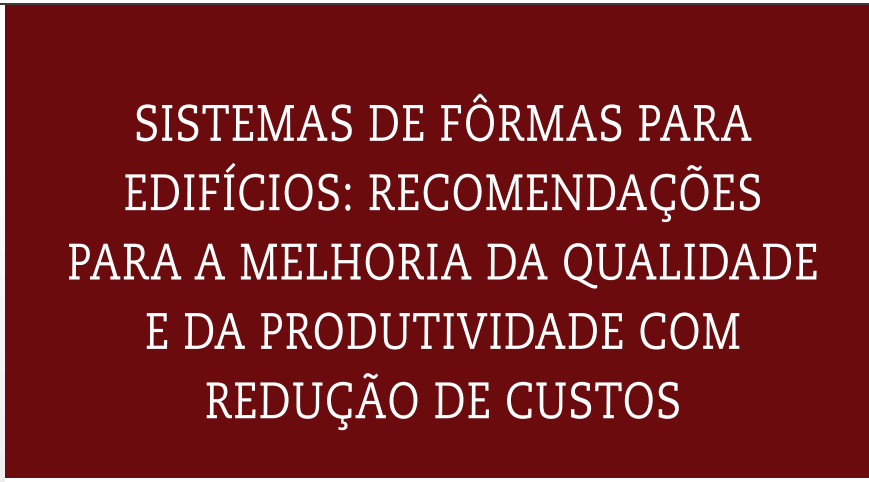

Autor: Antonio Carlos Zorzi

O livro propõe diretrizes para a racionalização de sistemas de fôrmas empregados na execução de estruturas de concreto armado e que utilizam o molde em madeira

As propostas foram embasadas na vasta experiência do autor, diretor de engenharia da Cyrela, sendo retiradas de sua dissertação de mestrado sobre o tema.

\section{DADOS TÉCNICOS}

ISBN 9788598576237

Formato: $18,6 \mathrm{~cm} \times 23,3 \mathrm{~cm}$ Páginas: 195

Acabamento: Capa dura Ano da publicação: 2015 $\underline{\text { Patrocínio }}$

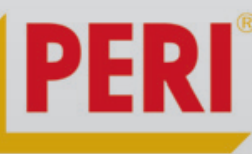

Aquisição: www.ibracon.org.br (Loja Virtual) 